\title{
Simulated Effects of Various Environmental Management Practices on Energy Consumption in Open and Confined Greenhouse Systems
}

\author{
I. Yildiz \\ Department of BioResource and \\ Agricultural Engineering \\ California Polytechnic State University \\ San Luis Obispo, CA 93407 \\ USA
}

\author{
D.P. Stombaugh \\ Department of Agricultural, Food, \\ and Biological Engineering \\ The Ohio State University \\ Columbus, OH 43210 \\ USA
}

Keywords: energy conservation, light management, $\mathrm{CO}_{2}$ dosing, minimum ventilation, greenhouse heating and cooling

\begin{abstract}
The objective of this study was to evaluate the effects of relative humidity, light management levels, minimum ventilation rates, $\mathrm{CO}_{2}$ enrichment and canopy size on energy consumption in three different greenhouse systems (conventional, open-loop heat pump, and confined heat pump) in winter, spring, and summer months. No difference was observed in energy consumption with relative humidity set point levels in winter due to the already low relative humidity levels. Some differences were observed in spring and summer due to extra dehumidification required to maintain the inside relative humidity at lower levels. Energy consumption in summer was reduced up to $25.5 \%$ by using an $80 \%$ relative humidity set point instead of $70 \%$ in the open heat pump system. Using a $250 \mathrm{~W} / \mathrm{m}^{2}$ light management level instead of $350 \mathrm{~W} / \mathrm{m}^{2}$ resulted in a $5 \%$ reduction in energy consumption in summer, but the energy used for ventilation and heating did not change in summer. The only change was observed in the energy required for cooling. However, the energy consumption was significantly affected by the minimum ventilation rate. A $50 \%$ reduction (using $0.005 \mathrm{~m}^{3} / \mathrm{s} . \mathrm{m}^{2}$ instead of 0.01 $\mathrm{m}^{3} / \mathrm{s} . \mathrm{m}^{2}$ ) in the minimum ventilation rate resulted in $26 \%, 21 \%$, and $1.5 \%$ decreases in total energy consumptions in winter, spring, and summer, respectively. Using a $\mathrm{CO}_{2}$ enrichment level of $1000 \mathrm{ppm}$ compared to an enrichment level of $350 \mathrm{ppm}$ resulted in a slight decrease in leaf temperatures during the day. This decrease caused a decrease in the air temperature resulting in slightly higher energy consumption for heating the greenhouse. This small increase in the energy consumption was about $1.7 \%$. The partial canopy $(0.4 \mathrm{~m})$ systems had more energy consumption than the full canopy $(2.0 \mathrm{~m})$ greenhouse systems.
\end{abstract}

\section{INTRODUCTION}

To provide economically optimal micro-environments for plant growth, producers can use or control the number of glazing layers, insulation curtains or screens to reduce long-wave radiation losses at night, reduced ventilation rates, evaporative coolers, and shading devices to control incoming solar radiation. In addition, a Rankine cycle heat pump that was developed by Yildiz (1993), and Yildiz et al. (1993) holds promise for reducing winter heating requirements and warm weather cooling loads. These systems involve complex tradeoffs between initial and operating costs for cooling and heating, plant responses to various environmental factors and the strategies used to regulate temperature, humidity and $\mathrm{CO}_{2}$ levels in the crop canopy. Special attention must also be given to the operational strategies associated with the use of heat pumps, especially in maintaining acceptable relative humidity levels within greenhouses.

A dynamic simulation model was developed and validated to provide an accurate prediction of greenhouse energy and moisture exchanges as a function of dynamic environmental factors (Yildiz and Stombaugh, 2006). This model was used to predict heating and cooling loads, and to evaluate the operational strategies associated with heating and cooling using the proposed heat pump and a conventional system. The heat 
pump was evaluated for both open and confined greenhouse systems, and these were compared to a conventionally ventilated and heated greenhouse. The specific objective of this study was to evaluate the effects of relative humidity, light management levels, minimum ventilation rates, $\mathrm{CO}_{2}$ enrichment and canopy size on energy consumption in three different greenhouse systems (conventional, open heat pump, and confined heat pump) in winter, spring, and summer.

\section{MATERIALS AND METHODS}

\section{Weather File}

January, April, and July weather files for Delaware (latitude $40^{\circ} 17^{\prime} \mathrm{N}$, longitude $\left.83^{\circ} 05^{\prime} \mathrm{W}\right)$, Ohio, U.S.A. were used to represent winter, spring, and summer in the simulations. Simulations were performed starting at the beginning of the fifth day and ended at the end of $29^{\text {th }}$ day of the month providing a 25-day simulation.

\section{Greenhouse Features, Heating, Cooling, Ventilation, Shading, and $\mathrm{CO}_{2}$ Dosing}

A dynamic computer simulation model to determine greenhouse microclimates was developed and validated. Table 1 shows the greenhouse and the crop characteristics used in this study. Yildiz and Stombaugh (2006) reported the theoretical approach, model validation, and all the other greenhouse and crop characteristics. The heat pumps evaluated for open (OHP) and confined (CHP) greenhouse systems were 3-ton (based on system heat removal capacity) gas fired units, and to provide multiposition proportional control it was assumed that 3 units were used in each greenhouse. The heat pump consists of a Rankine power cycle and a vapor compression cycle which uses a novel hydraulically connected rolling diaphragm piston cylinder device as motor, compressor and pump (Yildiz et al., 1993). R123 (dichlorotrifluoroethane) and R22 (chlorodifluoromethane) refrigerants were used for the power and refrigeration cycles, respectively. For the conventional greenhouse (CON) simulations, it was assumed that the conventional gas-fired furnace provided $24,612 \mathrm{~W}$ of heat input each. A furnace efficiency of 0.7 was assumed for the conventional heating system (Badger and Pole, 1979). No heat storage facility was used in this study. An overhead plastic tube was used for the hot and the cold air distribution in both heating and cooling modes. One of the heat pump units in the confined greenhouse system was used as a dehumidifier while operating as a heater. The only difference from the original heating unit was circulating the inside greenhouse air through the outdoor coil instead of the outside air. This prevented moisture build up in the confined greenhouse system. During the winter season, $0.943 \mathrm{~m}^{3} / \mathrm{s}$ of inside air passed through the condensers, and $2.829 \mathrm{~m}^{3} / \mathrm{s}$ of inside air was passed through the outside evaporator, which provided the dehumidification. An evaporative cooler was employed for cooling the conventional greenhouse. In the open and confined greenhouse systems, however, the heat pump units provided the cooling requirements in the greenhouse. Outdoor air was used in the evaporative cooling system, and it was assumed that the air at the evaporative cooler outlet was fully saturated. In the heat pump systems, indoor air was recirculated and introduced back to the inside at a lower temperature.

Two shading clothes with transmissivities of 0.75 and 0.50 were used to reduce the cooling loads. The use of these shading clothes provided shading levels of $25 \%, 50 \%$ and $62.5 \%$ by using them individually or together. An aluminized (both sides) night curtain was used at night to reduce the heat loss due to long-wave radiation exchanges between the inside greenhouse components and the sky. In the open systems (CON and OHP), ventilation was provided by two fans, one with a fixed flow rate to provide a minimum level of air exchange at all times, and the other one with a variable flow rate.

$\mathrm{CO}_{2}$ enrichment was provided in all three-greenhouse systems. Liquid $\mathrm{CO}_{2}$ tanks were employed and the enrichment was provided through a $\mathrm{CO}_{2}$ injector. $350 \mathrm{ppm}$ and $1000 \mathrm{ppm} \mathrm{CO}_{2}$ enrichment levels were evaluated. 


\section{Operational and Control Strategies}

The day or nighttime greenhouse temperature set points were based on the solar position. Based on the indoor air temperature, the control system operated in either the heating or cooling mode. If the system was in heating mode and if heating was required, the ventilation rate was first set to the minimum rate. The control system turned on other heating units based on the difference between the indoor and set point temperatures, providing a multi-position proportional control. If no heating was required in this mode no heating unit operated; but the system remained in the heating mode until it was switched to the cooling mode.

The cooling mode operated in two steps. The first step was to reduce the cooling load using a variable shading system and to cool the inside air by increasing ventilation rates. Two shading cloths provided the variable shading with transmissivities of 0.75 and 0.50 used individually or together. The minimum and maximum ventilation rates were $0.01 \mathrm{~m}^{3} / \mathrm{s} . \mathrm{m}^{2}$ (or half this rate) and $0.08 \mathrm{~m}^{3} / \mathrm{s} . \mathrm{m}^{2}$, respectively. If the first step in cooling could not handle the cooling load, then the second step was activated, in which the heat pump units (OHP) or evaporative cooling (CON) provided the cooling. In the conventional system, introducing an outside airflow rate of $0.08 \mathrm{~m}^{3} / \mathrm{s} . \mathrm{m}^{2}$ when the second step was activated in the cooling mode provided evaporative cooling. Relative humidity levels in the conventional system were controlled indirectly by the temperature control. In the open heat pump system, however, additional relative humidity control was provided. When the inside relative humidity levels exceeded relative humidity set points $(70 \%$ or $80 \%$ ), additional ventilation was introduced to decrease inside relative humidity. In the confined system, the same criterion was used to prompt the heating mode. However, the cooling mode was activated at lower inside temperatures than those used in the other two systems. The operation of the heating system was the same as in the other two systems. However, the minimum ventilation rate was used in the open system while no ventilation was used in the confined system. In the cooling mode of the confined system, there was only one step unlike the conventional and open heat pump systems, which had two-step cooling systems. Here, no cooling was provided by ventilation; instead, the cooling was provided by the three heat pump units providing a multiposition proportional control, after reducing the cooling load using the variable shading system. The operation of the shading system was the same as in the other two systems. Either the cooling units or the dehumidifier (the first heating unit) controlled inside relative humidity. When the inside relative humidity levels exceeded relative humidity set points $(70 \%$ or $80 \%)$, this heating unit operated as a dehumidifier to prevent excess moisture within the confined greenhouse system.

\section{RESULTS AND DISCUSSION}

The effect of relative humidity management levels on energy consumption was determined in open and confined heat pump greenhouse systems. Table 2 summarizes the findings with respect to relative humidity set points of $70 \%$ and $80 \%$ in both greenhouse systems in winter, spring, and summer. No difference was observed in energy consumption in winter, due to the already low relative humidity levels. However, some differences in energy use with respect to the relative humidity management levels were observed in spring and summer. This was due to the extra dehumidification necessary to maintain the inside relative humidity levels at the desired set points. As a result, more energy was consumed to maintain the inside relative humidity at lower levels. Energy consumption (in summer) was reduced up to $25.5 \%$ by using an $80 \%$ set point instead of $70 \%$ in the open heat pump greenhouse system.

Table 3 summarizes the effect of light management levels with different relative humidity set point levels on energy consumption in summer. Low light level refers to a shading set point of $250 \mathrm{~W} / \mathrm{m}^{2}$, while the high light level refers to a shading set point of $350 \mathrm{~W} / \mathrm{m}^{2}$ inside the greenhouse. The energy use for ventilation and heating did not change at all in summer. The only change was observed in the energy required for cooling. This obviously resulted from the reduced cooling loads due to the reduced solar 
loads in the low light greenhouse system. Using $250 \mathrm{~W} / \mathrm{m}^{2}$ light management level instead of $350 \mathrm{~W} / \mathrm{m}^{2}$ resulted in a $5 \%$ reduction in energy consumption in summer.

The effect of minimum ventilation on energy consumption in an open heat pump greenhouse system was evaluated. For this assessment, a minimum ventilation rate of $0.005 \mathrm{~m}^{3} / \mathrm{s} . \mathrm{m}^{2}$ was used instead of the rate of $0.01 \mathrm{~m}^{3} / \mathrm{s} . \mathrm{m}^{2}$ that was the minimum ventilation rate used in all the other simulations. Table 4 shows that energy consumption was significantly affected by the variation in minimum ventilation rate. A $50 \%$ decrease in the ventilation rate resulted in $26 \%, 21 \%$, and $1.5 \%$ decreases in total energy consumption in winter, spring, and summer, respectively. In winter, $26 \%$ and $50 \%$ drops were observed in heating and ventilation energy consumption, respectively. This showed that a $50 \%$ reduction in minimum ventilation rate resulted in a $50 \%$ reduction in energy consumption for ventilation in winter. This was due to the nearly continuous use of minimum ventilation rates in winter. A $50 \%$ reduction in the minimum ventilation rate for spring, however, resulted in only a $15 \%$ decrease in energy consumption. This indicated that ventilation rates higher than the minimum were used for some time due to increased relative humidity levels within the greenhouse. The effect of minimum ventilation rate in summer was insignificant for the same reasons that were determined for spring.

Table 5 summarizes the simulated effects of $\mathrm{CO}_{2}$ enrichment on energy consumption in spring. A number of studies reported that elevated $\mathrm{CO}_{2}$ concentration reduces the transpiration of plants due to increased stomatal resistance and enhanced leaf area index (LAI) (Mortensen, 1987; Tremblay and Gosselin, 1998; Allen et al., 2003; Li et al., 2003; Baker, 2005; Bhatt et al., 2007). Effect of $\mathrm{CO}_{2}$ enrichment on energy consumption in our study was caused mainly due to self-shading resulting from the enhanced LAI, not due to stomatal acclimation. Stomatal resistance to water vapor in this study was defined as a function of solar radiation derived from daytime data only, hence slightly overestimating night-time transpiration. The stomatal resistance to $\mathrm{CO}_{2}$ was approximated from that to water vapor and the ratio of corresponding diffusivities in air. By reducing light penetration through the canopy, the enhanced self-shading at elevated $\mathrm{CO}_{2}$ enrichment decreased transpiration especially at the middle and bottom of the canopy. This is in agreement with the findings provided by Li et al. (2003). In another study, Li et al. (2004) reported that the $\mathrm{CO}_{2}$ enrichment-induced decrease in transpiration almost compensated for the increase in transpiration brought by the higher leaf area. Similar findings were reported in a number of studies (Mauney et al., 1994, Kimbal et al., 1999, 2002; Triggs et al., (2004)) stating that crops with large growth responses to elevated $\mathrm{CO}_{2}$ had near zero water savings while crops with modest growth responses had a water savings of about $7 \%$. This has energy consequences as well. In our simulation study, $\mathrm{CO}_{2}$ enrichment during the day caused a decrease in leaf and air temperatures. Daytime decrease in the air temperature was $0.4^{\circ} \mathrm{C}$. The reason for the temperature decrease was the increase in LAI and self-shading, as well as the increase in metabolic activity (high $\mathrm{CO}_{2}$ fixation) due to the $\mathrm{CO}_{2}$ enrichment during the day. The temperature decrease resulted in slightly higher energy consumption for heating the greenhouse (Table 5 ). This small increase in the energy consumption was about $1.7 \%$. Although preliminary comparisons with some previous studies seemed promising, further experimental validation have been planned to see where exactly they fit in the literature.

Table 6 summarizes the differences in energy consumption with respect to different canopy sizes in winter. Partial canopy $(0.4 \mathrm{~m})$ had higher energy consumption than the full canopy $(2.0 \mathrm{~m})$ for the crop architectural parameters provided in Table 1. The same average leaf dimensions were used in both cases, LAI was defined as a function of plant height, and foliage area along the row direction was uniformly distributed. The model included a description of growth in height since absorption at a given level can not be determined from only LAI, but also depends on the geometry of canopy stand, the amount of diffuse and direct solar radiation. Yang et al. (1990) found that most of the daytime transpiration was from the top layer of the canopy where most of the solar radiation was intercepted. High water vapor content, low airflow, and old leaves in the lower part of the canopy all contributed to inverse (increasing with height) distribution of 
transpiration rate. This was also in agreement with the finding that transpiration rate of a mature plant canopy was not proportional to the size of the stand or LAI (Yang et al., 1989). Rather, it generally approached a maximum value regulated by radiation availability and other variables. Our findings also were in agreement with their observations. The partial canopy stand had more exposed surfaces (both the canopy stand and reflective floor) for longwave radiation exchange with the greenhouse glazing and sky. It should also be emphasized that stomatal resistance to water vapor in this study was defined only as a function of solar radiation. This partially concealed the true effect of canopy height on energy consumption. Partial canopy stand had improved light penetration and higher leaf exposures to light as well, resulting in higher transpiration (approximately 6\%) and enhanced metabolic rates. This also means that more energy (required for transpiration and metabolic activities) was extracted by plant elements from the surrounding air. This is also in agreement with the findings of Yang et al. (1990). These were probably the major reasons for the increased energy use for heating in the partial canopy systems. A full canopy stand, however, covered the entire floor surface, leaving no exposed floor or canopy sides for longwave radiation exchange, and had high water vapor content and low airflow within the canopy all contributing relatively lower transpiration rates. Here as well, further experimental validation for specific crops have been planned to see the complex relationship between the crop architectural parameters and energy consumption.

\section{CONCLUSIONS}

In the confined heat pump system, using different relative humidity set points resulted in almost the same relative humidity regimes. No difference was observed in the open heat pump system as well in winter, because the inside relative humidity levels never reached the $70 \%$ and $80 \%$ set points. Some differences were observed in spring and summer due to the extra dehumidification required. Energy consumption (in summer) was reduced up to $25.5 \%$ by using an $80 \%$ set point instead of $70 \%$ in the open heat pump system. Using a $250 \mathrm{~W} / \mathrm{m}^{2}$ light management level instead of $350 \mathrm{~W} / \mathrm{m}^{2}$ resulted in a $5 \%$ reduction in energy consumption in summer, but the energy used for ventilation and heating did not change in summer. The only change was observed in the energy required for cooling. Energy consumption was significantly affected by the minimum ventilation rate. A $50 \%$ reduction in the minimum rate resulted in $26 \%, 21 \%$, and $1.5 \%$ decreases in total energy consumption in winter, spring, and summer, respectively. The $\mathrm{CO}_{2}$ enrichment caused a slight decrease in leaf temperatures during the day, due to the complex relationships between transpiration, and stomatal resistance, crop architectural parameters and metabolic activity. The overall relationship resulted in slightly higher $(1.7 \%)$ energy consumption for heating. The partial canopy greenhouse systems had more energy consumption than the full canopy greenhouse systems.

\section{ACKNOWLEDGEMENTS}

The authors gratefully acknowledge the American Society of Heating, Refrigerating, and Air-Conditioning Engineers, Inc. and Ohio Super Computing Center for providing partial funding for this study. They would also like to extend their appreciation to the reviewers for their valuable suggestions.

\section{Literature Cited}

Allen, L.H., Pan, D., Boote, K.J., Pickering, N.B. and Jones, J.W. 2003. Carbon dioxide and temperature effects on evapotranspiration and water use efficiency of soybean. Agronomy Journal 95: 1071-1081.

Badger, P.C. and Poole, H.A. 1979. Conserving Energy in Greenhouses. OARDC Special Cir. 102, Extension Bul. 651, p. 32. Ohio Agricultural Research and Development Center, Wooster, Ohio, U.S.A.

Baker, J.T. 2005. Rice growth, yield and photosynthetic responses to elevated atmospheric carbon dioxide concentration and drought. Journal of Crop Improvement 
$13(1 / 2): 7-30$.

Bhatt, R.K., Baig, M.J. and Tiwari, H.S. 2007. Growth, biomass production, and assimilatory characters in Cenchrus ciliaris L. under elevated $\mathrm{CO}_{2}$ condition. Photosynthetica 45 (2): 296-98.

Kimball, B.A., LaMorte, R.L., Pinter Jr., P.J., Wall, G.W., Hunsaker, D.J., Adamsen, F.J., Leavitt, S.W., Thompson, T.L., Matthias, A.D. and Brooks, T.J. 1999. Free-air $\mathrm{CO}_{2}$ enrichment (FACE) and soil nitrogen effects on energy balance and evapotranspiration of wheat. Water Resources Res. 35 (4):1179-1190.

Kimball, B.A., Kobayashi, K. and Bindi, M. 2002. Responses of agricultural crops to free-air $\mathrm{CO}_{2}$ enrichment. Adv. Agron. 77:293-368.

Li, J.H., Dugas, W.A., Hymus, G.J., Johnson, D.P., Drake, B.G. and Hungate, B.A. 2003. Direct and indirect effects of elevated $\mathrm{CO}_{2}$ on transpiration from Quercus myrtifolia in a scrub-oak ecosystem. Global Change Biology 9 (1): 96-105.

$\mathrm{Li}$, F., Kang, S. and Zhang, J. 2004. Interactive effects of elevated $\mathrm{CO}_{2}$, nitrogen and drought on leaf area, stomatal conductance, and evapotranspiration of wheat. Agricultural Water Management 67 (3): 221-233.

Mauney, J.R., Kimball, B.A., Pinter Jr., P.J., LaMorte, R.L., Lewin, K.F., Nagy, J. and Hendrey, G.R. 1994. Growth and yield of cotton in response to a free-air carbon dioxide enrichment (FACE) environment. Agric. For. Meteorol. 70:49-67.

Mortensen, L. M. 1987. Review: $\mathrm{CO}_{2}$ enrichment in greenhouses, crop responses Scientia Hort. 33: 1-25.

Tremblay, N. and Gosselin, A. 1998. Effect of carbon dioxide enrichment and light. HortTechnology 8 (4): 524-28.

Triggs, J.M., Kimball, B.A., Pinter, P.J., Wall, G.W., Conley, M.M., Brooks, T.J., LaMorte, R.L., Adam, N.R., Ottman, M.J., Matthias, A.D., Leavitt, S.W. and Cerveny, R.S. 2004. Free-air $\mathrm{CO}_{2}$ enrichment effects on the energy balance and evapotranspiration of sorghum. Agricultural and Forest Meteorology 124 (1-2):63-79.

Yang, X., Short, T.H., Fox, R.D. and Bauerle, W.L. 1989. The microclimate and transpiration of a greenhouse cucumber crop. Trans. of the ASAE 32 (6):2143-2150.

Yang, X., Short, T.H., Fox, R.D. and Bauerle, W.L. 1990. Plant architectural parameters of a greenhouse cucumber row crop. Agric. and Forest Meteorol. 51: 93-105.

Yildiz, I., Lin, C., and Christensen, R.N. 1993. A performance study of a Rankine cycle driven heat pump system. AES-Vol. 29, Heat Pump and Refrigeration Systems Design, Analysis, and Applications. ASME 1993. U.S.A.: 9-18.

Yildiz, I. and Stombaugh, D.P. 2006. Dynamic modeling of microclimate and environmental control strategies in a greenhouse coupled with a heat pump system. Acta Hort. 718:331-340. 


\section{$\underline{\text { Tables }}$}

Table 1. Greenhouse and crop characteristics used in the simulation model.

Greenhouse length

Greenhouse width

Greenhouse height at eaves

Greenhouse height at ridges

Glazing

Floor surface material

Crop type

Crop row orientation

Full plant height, $\mathrm{h}$

Distance between plant rows, $\mathrm{W}$

Width of row stand, $w$

Leaf area index, LAI

Avg. leaf length

Avg. leaf width

OHP: Open Heat Pump; CHP: Confined Heat Pump. ${ }^{*}$ Cited from Yang et al. (1990)
$7.5 \mathrm{~m}$ (Conventional and OHP) and 25.m (CHP)

$7.5 \mathrm{~m}$

$2.5 \mathrm{~m}$

$4.5 \mathrm{~m}$

Double polyethylene

Reflective mulch

Cucumber

North - South

$2.0 \mathrm{~m}$

$0.86 \mathrm{~m}$

$\mathrm{w}=0.8[1-\exp (1.449 \mathrm{~h})]^{*}$

$\mathrm{LAI}=0.886 \mathrm{~h}-0.0965^{\circ}$

$0.30 \mathrm{~m}$

$0.25 \mathrm{~m}$

Table 2. Energy consumption with respect to relative humidity levels in the open heat pump (OHP) and confined heat pump (CHP) greenhouse systems in winter, spring, and summer.

\begin{tabular}{lcccccc}
\hline & \multicolumn{2}{c}{ CHP } & \multicolumn{2}{c}{ OHP } & \multicolumn{2}{c}{ CON } \\
\hline Canopy Size: & Partial $^{*}$ & Full** & Partial & Full & Partial & Full \\
Energy (MJ $/$ day. $\left.\mathrm{m}^{2}\right)$ & & & & & & \\
$\quad$ Heating & 14.06 & 11.34 & 29.23 & 23.45 & 72.42 & 56.92 \\
Cooling & 0.05 & 0.02 & --- & --- & --- & --- \\
$\quad$ Ventilation & --- & --- & 0.11 & 0.11 & 0.11 & 0.11 \\
$\quad$ Total & 14.12 & 11.36 & 29.34 & 23.56 & 72.53 & 57.03 \\
\hline
\end{tabular}

Table 3. Energy consumption with respect to light management levels in the open heat pump (OHP) greenhouse system (summer).

\begin{tabular}{lccccccccccccc}
\hline & \multicolumn{3}{c}{ Winter } & \multicolumn{4}{c}{ Spring } & \multicolumn{4}{c}{ Summer } \\
& \multicolumn{2}{c}{ CHP } & \multicolumn{2}{c}{ OHP } & \multicolumn{2}{c}{ CHP } & \multicolumn{1}{c}{ OHP } & \multicolumn{2}{c}{ CHP } & OHP \\
\hline Rel. Humidity Set Point: & $70 \%$ & $80 \%$ & $70 \%$ & $80 \%$ & $70 \%$ & $80 \%$ & $70 \%$ & $80 \%$ & $70 \%$ & $80 \%$ & $70 \%$ & $80 \%$ \\
Avg. Inside Rel. Hum. : & $84 \%$ & $84 \%$ & $36 \%$ & $36 \%$ & $85 \%$ & $86 \%$ & $66 \%$ & $68 \%$ & $89 \%$ & $89 \%$ & $78 \%$ & $82 \%$ \\
Energy (MJ/day.m ${ }^{2}$ ) & & & & & & & & & & & & \\
$\quad$ Heating & 11.59 & 11.34 & 23.45 & 23.45 & 5.49 & 5.31 & 10.51 & 8.82 & 0.70 & 0.65 & 0.25 & 0.10 \\
$\quad$ Cooling & 0.03 & 0.02 & --- & --- & 2.04 & 2.02 & --- & --- & 5.40 & 5.41 & 1.28 & 0.94 \\
$\quad$ Ventilation & --- & --- & 0.11 & 0.11 & --- & --- & 0.32 & 0.23 & --- & --- & 0.81 & 0.71 \\
$\quad$ Total & 11.62 & 11.36 & 23.56 & 23.56 & 7.53 & 7.53 & 10.83 & 9.04 & 6.10 & 6.06 & 2.35 & 1.75 \\
\hline
\end{tabular}


Table 4. Energy consumption with respect to minimum ventilation rate in the open heat pump system (OHP) in winter, spring, and summer.

\begin{tabular}{lcccc}
\hline Shading Level: & \multicolumn{2}{c}{$200-250 \mathrm{~W} / \mathrm{m}^{2}$} & \multicolumn{2}{c}{$300-350 \mathrm{~W} / \mathrm{m}^{2}$} \\
Rel. Humidity Set Point: & $70 \%$ & $80 \%$ & $70 \%$ & $80 \%$ \\
Energy (MJ/day.m $\mathrm{m}^{2}$ ) & & & & \\
\hline Heating & 0.25 & 0.10 & 0.25 & 0.10 \\
Cooling & 1.28 & 0.94 & 1.37 & 1.03 \\
Ventilation & 0.82 & 0.71 & 0.82 & 0.72 \\
TOTAL & 2.35 & 1.75 & 2.44 & 1.85 \\
\hline
\end{tabular}

Table 5. Energy consumption with respect to $\mathrm{CO}_{2}$ enrichment levels (spring).

\begin{tabular}{lcccccc}
\hline & \multicolumn{2}{c}{ CHP } & \multicolumn{2}{c}{ OHP } & \multicolumn{2}{c}{ CON } \\
& $350 \mathrm{ppm}$ & $1000 \mathrm{ppm}$ & $350 \mathrm{ppm}$ & $1000 \mathrm{ppm}$ & $350 \mathrm{ppm}$ & $1000 \mathrm{ppm}$ \\
\hline Energy (MJ/day.m ${ }^{2}$ ) & & & & & & \\
Heating & 5.49 & 5.95 & 10.51 & 10.61 & 20.61 & 20.97 \\
Cooling & 2.04 & 1.48 & --- & -- & -- & -- \\
Ventilation & --- & --- & 0.32 & 0.32 & 0.11 & 0.11 \\
TOTAL & 7.53 & 7.43 & 10.83 & 10.93 & 20.73 & 21.08 \\
\hline
\end{tabular}

Table 6. Energy consumption with respect to canopy size in conventional (CON), open heat pump (OHP), and confined heat pump (CHP) greenhouse systems in winter.

\begin{tabular}{lcccccc}
\hline & \multicolumn{2}{c}{ Winter } & \multicolumn{2}{c}{ Spring } & \multicolumn{2}{c}{ Summer } \\
\hline Vent Rate $\left(\mathrm{m}^{3} / \mathrm{s}^{2} \mathrm{~m}^{2}\right):$ & 0.01 & 0.005 & 0.01 & 0.005 & 0.01 & 0.005 \\
Energy $\left(\mathrm{MJ} /\right.$ day.m $\left.\mathrm{m}^{2}\right)$ & & & & & & \\
$\quad$ Heating & 23.45 & 17.41 & 8.82 & 6.95 & 0.10 & 0.10 \\
Cooling & --- & --- & --- & -- & 0.94 & 0.93 \\
$\quad$ Ventilation & 0.11 & 0.06 & 0.23 & 0.19 & 0.71 & 0.71 \\
$\quad$ TOTAL & 23.56 & 17.47 & 9.04 & 7.15 & 1.75 & 1.73 \\
\hline
\end{tabular}

*0.4 m canopy stand; **2.0 m canopy stand. 